\title{
Avaliação no contexto socioeducativo: desafios e perspectivas
}

\author{
Assessment in the socio-educational context: \\ challenges and perspectives \\ DEnilvia Rocha Morato Soares \\ Secretaria de Estado de Educação do Distrito Federal - SEEDF \\ enilvia@hotmail.com \\ Edileuza Fernandes Silva \\ Universidade de Brasília - UnB \\ edileuzafeunb@gmail.com
}

Resumo: Compreender a avaliação conduzida em um Núcleo de Ensino de uma Unidade de Internação Socioeducativa do DF constitui objetivo de pesquisa discutida neste artigo. Por meio de estudo de caso do tipo etnográfico, utilizou-se para levantamento de dados: observação, questionários, entrevistas semiestruturadas e grupos focais. Fundamentadas no materialismo histórico-dialético, as análises consideraram as categorias metodológicas apontadas por Cury (1985) e as conceituais emersas das significações (AGUIAR; OZELLA, 2006, 2013; AGUIAR; SOARES; MACHADO, 2015) constituídas por interlocutores. O estudo indicou a necessidade de espaços-tempos coletivos e democráticos que viabilizem uma prática avaliativa com condições de contribuir para a instauração de uma política educacional intersetorial favorável à articulação do trabalho realizado pelo Núcleo de Ensino e demais setores da Unidade de Internação. Avaliar e planejar conjuntamente o processo formativo dos jovens internos concorreria para o enfrentamento de desafios que obstaculizam o direito de aprender, legalmente assegurado a todos os socioeducandos.

Palavras-chave: Avaliação. Socioeducação. Trabalho pedagógico. Política intersetorial.

Abstract: Understanding the evaluation conducted in a Teaching Center of a Socio-educational Inpatient Unit in the Federal District is the aim of the research discussed in this article. Through an ethnographic case study, data collection was used: observation, questionnaires, semi-structured interviews and focus groups. Based on historical-dialectical materialism, the analyzes considered the methodological categories pointed out by Cury (1985) and the conceptual ones emerged from the meanings (AGUIAR; OZELLA, 2006, 2013; AGUIAR; SOARES; MACHADO, 2015) constituted by the interlocutors. The study indicated the need for collective and democratic spaces-times that enable an evaluative practice that would contribute to the establishment of an intersectoral educational policy favorable to the articulation of the work carried out by the Teaching Center and other sectors of the Inpatient Unit. Jointly evaluating and planning the training process of young inmates would contribute to facing challenges that hinder the right to learn, legally guaranteed to all socio-educational students.

Keywords: Evaluation. Socio-education. Pedagogical work. Intersectoral policy. 


\section{Introdução}

Ao estabelecer valores democráticos e humanos em defesa da criança e do adolescente, garantindo prioridade na atenção aos seus direitos fundamentais, bem como a observância de sua condição peculiar de pessoas em desenvolvimento, a Constituição Federal de 1988 abre caminhos para a consolidação da doutrina de proteção integral, legislada no Estatuto da Criança e do Adolescente (ECA) em 1990.

Embora institua regras especiais para o adolescente autor de prática infracional, prescrevendo a aplicação de medidas socioeducativas, a ausência de regras e propostas pedagógicas claras no ECA (BRASIL, 1990) sinalizou a necessidade de um instrumento legal com condições de regular e disciplinar sua aplicação.

Em atendimento a essa demanda, foi aprovado, em 2012, o Projeto de Lei $n^{\circ}$ 1.627/07, posteriormente convertido na Lei $n^{\circ} 12.594$, que contém as diretrizes para a execução das medidas socioeducativas. Institui-se, assim, o Sistema Nacional de Atendimento Socioeducativo - SINASE (BRASIL, 2006) visando reafirmar a natureza pedagógica das medidas destinadas ao atendimento de adolescentes em situação de ato infracional.

O SINASE constitui um subsistema do Sistema de Garantia de Direitos (SGD) e se articula aos demais subsistemas que o integram (Saúde, Educação, Assistência Social, Justiça e Segurança Pública) para assegurar, por meio de instrumentos normativos, mecanismos que possibilitam promover, defender e controlar a efetivação dos direitos de crianças e adolescentes. (SOUZA e BATISTA, 2008).

A responsabilidade de cada pasta por suas atribuições, bem como a articulação entre elas é imprescindível para uma maior efetividade das práticas voltadas à proteção integral da criança e do adolescente. Cabe aos órgãos deliberativos e gestores do SINASE estimular a prática intersetorial que atende ao princípio da incompletude institucional, norteador dos programas e da rede de serviços voltada ao atendimento socioeducativo.

A lógica da instituição total assentada no entendimento de que uma única instituição deva ocupar-se de suprir todas as necessidades dos sujeitos por ela atendidos, deve ser banida e substituída pela articulação entre as diferentes instituições. Isso implica dizer que os programas socioeducativos não dão conta, sozinhos, das necessidades de atendimento ao socioeducando, requerendo a conexão entre diferentes políticas. 
No Distrito Federal (DF), a intersetorialidade é proposta nas Diretrizes Pedagógicas Escolarização na Socioeducação (DISTRITO FEDERAL, 2014, p. 35), ao indicar que compete “aos profissionais da Educação uma relação de cooperação com os demais setores e políticas presentes na Unidade de Internação." O trabalho pedagógico desenvolvido junto aos socioeducandos requer, portanto, uma dinâmica que permita não só integrar as diferentes esferas que compõem o contexto escolar, mas estender-se ao âmbito de toda a Unidade de Internação (UI).

Sendo a avaliação um elemento estruturante e articulador do trabalho pedagógico, este artigo discute a possibilidade de que, em contexto socioeducativo, ela possa contribuir para integrar o trabalho escolar ao trabalho desenvolvido pelas demais instâncias da UI. Em decorrência disso, deve ajudar a superar obstáculos que se apresentem diante do desafio de ensinar adolescentes e jovens ${ }^{1}$ internos para cumprimento de medida socioeducativa.

A pesquisa viabilizadora de tal apontamento desenvolveu-se por meio de abordagem qualitativa e delineou-se como estudo de caso do tipo etnográfico. Para levantamento de informações no campo empírico, foram utilizados: observação participante de aulas; grupos focais com socioeducandos; aplicação de questionários a professores, coordenadora e supervisor pedagógico do Núcleo de Ensino (NE); e entrevistas semiestruturadas com professores, coordenadora e supervisor pedagógico do NE, pedagogas da equipe sociopsicopedagógica da UI e Juíza Titular da Vara de Execução de Medidas Socioeducativas. Fundamentadas pelo materialismo histórico-dialético, as análises foram construídas a partir da articulação entre as categorias metodológicas apontadas por Cury (1985) para o campo da educação (contradição, totalidade, mediação, reprodução e hegemonia) e das categorias conceituais emersas do movimento de articulação dos núcleos das significações (AGUIAR e OZELLA, 2006 e 2013; AGUIAR, SOARES e MACHADO, 2015) constituídas por professores e estudantes sobre a avaliação.

A educação no SINASE: voltada para o social ou utopia a ser alcançada?

A educação é apresentada no SINASE (BRASIL, 2006) como um dos eixos estratégicos² que paramentam a ação socioeducativa. Segundo o documento, deve ser garantido ao adolescente em atendimento socioeducativo o acesso a todos os níveis de educação formal de acordo com as suas necessidades específicas, propiciando condições adequadas à apropriação e produção de conhecimento. Fica aí subentendido (ou mesmo explícito) o dever da escola de criar mecanismos 
para que todos os socioeducandos aprendam durante o período em que estiverem cumprindo medida socioeducativa.

Entretanto, a distorção idade-série em turmas das Unidades de Internação corresponde $\mathrm{a}^{3}$ : 66,1\% nos anos iniciais do Ensino Fundamental; 88,23\% nos anos finais do Ensino Fundamental e 59,91\% no Ensino Médio. Em turmas regulares tem-se: 14,1\% de distorção nos anos iniciais; 27,3\% nos anos finais e 28,2\% no Ensino Médio. A distância entre os resultados de desempenho dos estudantes internos em relação aos que frequentam instituições educativas regulares mostra-se preocupante e nos leva a refletir sobre a organização do trabalho pedagógico dessas Unidades que requerem dos profissionais um trabalho que atente para as especificidades dos estudantes e para a necessidade de uma pedagogia diferenciada que não ignore o "objetivo primordial da escola que é o de tentar garantir que todos os alunos tenham acesso a uma cultura de base comum" (PERRENOUD, 1999, p. 12). Considerar as diferenças é organizar situações didático-pedagógicas favoráveis às aprendizagens de todos, independentemente de sua condição social, econômica e cultural.

Uma educação voltada para o social deveria ser a tônica do processo educativo de todos os estudantes, indistintamente. Formar com qualidade referenciada nos sujeitos sociais traz implícita a ideia de preparar para uma atuação crítica e potencializadora de relações humanas e solidárias, o que requer pedagogias diferenciadas. O elevado índice de estudantes (internos ou não) cujo acompanhamento escolar não atende ao estabelecido socialmente pela escola indica que uma formação de cunho social é ainda uma utopia a ser alcançada.

Em relação à escolarização de pessoas reclusas por cometimento de ato ilícito, Scarfó Breglia e Frejtman (2011, p. 158) asseguram que as possibilidades da educação "vão além das opções reais de inserção social e econômica que esta gera, pois trata-se de um valor em si mesma, por isso é um direito humano, por isso deve estar garantida para toda a população". É no espaço escolar que, segundo Onofre (2011, p. 277), “o homem busca a sua identidade e o diálogo, reconstrói a sua história e valoriza os momentos de aprendizagem, tendo, portanto, o direito a uma escola competente, produtiva e libertadora".

As assertivas dos autores possibilitam inferir que um trabalho de reintegração social feito por meio de mecanismos que ultrapassam a repressão passa, necessariamente, por uma educação escolar que consista em oportunidade real de aprender. Ainda que tomada como punição autorizada e justificada, a internação de adolescentes e jovens em conflito com a lei não pode priválos de seus direitos, especialmente quando esses são capazes de concorrer para o êxito de sua vida extra institucional, como é o caso da educação escolar. Scarfó e Aued (2013, p. 89) confirmam esse 
pressuposto ao elencar a educação de adolescentes e jovens presos como "direito chave", uma vez que lhes abre portas ao conhecimento dos demais direitos, muitas vezes negados ou violados, e possibilita o reconhecimento de si mesmos como sujeitos de direitos.

Há, então, que se propor uma escola que respeite o socioeducando quanto às suas necessidades e especificidades de ser único, especial e singular, assegurando-lhe uma experiência educativa facilitadora da construção de saberes indispensáveis ao seu retorno à sociedade e potencializadora do exercício crítico e consciente de seus direitos. Tomada dessa forma, a educação escolar oferecida nas Unidades de Internação pode contribuir para que o período de reclusão dos socioeducandos constitua tempo de formação, de conquistas e de superação.

A intersetorialidade insurge nesse contexto como paradigma norteador do trabalho desenvolvido no âmbito dessas instituições por possibilitar agregar diferentes visões e iniciativas que priorizem o aspecto educativo sobre o punitivo e, em decorrência, garantam aos adolescentes e jovens internos os direitos que lhes são legalmente assegurados. Dada a relevância da avaliação que se desenvolve no âmbito das instituições para o (re)direcionamento do trabalho das UI e das escolas que funcionam no seu interior, ela foi aqui tomada como foco de análise da realidade estudada.

Vale destacar que o modo de produção que caracteriza nossas concretas condições sociais, diminuindo as chances de êxito de iniciativas com propósitos progressistas, não são aqui desconsideradas. Entretanto, não podemos esperar que o sistema mude para depois mudar a escola. “São lutas simultâneas" (VASCONCELLOS, 2014, p. 27). É preciso, portanto, vislumbrar possibilidades para, então, projetar caminhos.

\section{O Núcleo de Ensino e o diálogo com a Unidade de Internação: a avaliação em foco}

A conquista do sonho dos jovens internos de retornarem à vida em liberdade transita por diferentes caminhos que ora se cruzam ora se desenlaçam até o momento em que seus destinos são definidos, podendo suas investidas nesse sentido lograrem êxito ou não. Toda essa trajetória segue, em contexto socioeducativo, permeada por avaliações de toda ordem provindas de diferentes segmentos (profissionais da área da saúde, segurança, educação e assistência social; familiares; colegas e religiosos) até a avaliação final que, à época da pesquisa, ficava a cargo da justiça, representada pela juíza responsável pela Vara de Execução de Medidas Socioeducativas da Vara da Infância e da Juventude do Distrito Federal. Essa última avaliação constitui, na realidade, uma reavaliação da medida socioeducativa imposta, nesse caso, de internação estrita. 
As decisões dessa profissional quanto a manutenção, suspensão ou substituição da medida socioeducativa em cumprimento eram referenciadas por informações diversas a respeito dos socioeducandos, que eram a ela prestadas periodicamente pela equipe sociopsicopedagógica (psicólogos, pedagogos e assistentes sociais) de cada UI, por meio de um documento intitulado Relatório Avaliativo (RA).

As informações registradas nos RA ganham, assim, grande importância para os socioeducandos, não só por possibilitar acompanhá-los durante o processo de ressocialização, mas também por subsidiar as decisões judiciais que são tomadas a seu respeito. Devem, portanto, ser capazes de comunicar, com a maior precisão possível, sobre o desenvolvimento desses jovens. Essa não foi, no entanto, a realidade identificada no campo investigado.

Os RA contavam com dados produzidos pela Gerência de Segurança, pela Gerência de Saúde e pela Gerência Sociopsicopedagógica (GESPP), sendo esta última responsável por informar, entre outros, aspectos referentes ao desempenho escolar dos socioeducandos. Cabia ao Núcleo de Ensino (NE) produzir e registrar essas informações em um documento chamado "Ficha Instrumental Pedagógica" que, posteriormente, era encaminhado à GESPP para que os dados ali contidos fossem incorporados ao Relatório Avaliativo da UI e enviados à Vara de Execução de Medidas Socioeducativas.

A Ficha Instrumental (FI) continha, além de itens referentes ao comportamento dos estudantes, aspectos de natureza pedagógica. Nela, deveriam ser especificados, além dos conhecimentos referentes a leitura, interpretação e produção de texto e a interpretação e resolução de situações que exigiam raciocínio lógico-matemático, as dificuldades de aprendizagem evidenciadas pelos estudantes e as providências adotadas visando ajudá-los a superá-las, bem como as potencialidades e habilidades por eles manifestadas no processo ensino-aprendizagem e as sugestões de ações para o aproveitamento delas.

As informações solicitadas na FI não se limitavam, portanto, a constatações. A requisição do relato das providências adotadas frente às dificuldades evidenciadas pelos estudantes e das sugestões de ações para o aproveitamento de suas habilidades e potencialidades sinalizam interesse em desenvolver um processo avaliativo formativo, uma vez que a 'formatividade' da avaliação requer esforço para compreender melhor como as coisas se passam a fim de aperfeiçoar (HADJI, 2001). O caráter formativo da avaliação é, portanto, potencializado pelo movimento que gera a partir do que se constata e, de acordo com Sadler (1989), deve produzir um efeito de progressão 
com satisfação, mas que, no entanto, estimule o aluno a continuar, mesmo na presença de desafios e obstáculos como os presentes no cumprimento de medidas socioeducativas.

Contraditoriamente, 15 dos 25 professores consultados a respeito das informações registradas nas Fichas Instrumentais afirmaram que não as utilizavam para organizar e desenvolver o seu trabalho. Para esses professores, o registro das condições de aprendizagem dos estudantes limitava-se à condição de parecer técnico e burocrático inibidor de intervenções por ele fundamentadas. As descrições de encaminhamentos diante da realidade cientificada tornam-se, assim, uma atividade puramente formal capaz de desprover a avaliação de sua possibilidade formativa. A alienação do trabalhador, cujas raízes se encontram no modo de produção capitalista de exploração do homem pelo homem, destituindo-o do domínio do próprio trabalho, parece estar presente nesse processo quando professores se distanciam da dimensão política e humana que deve mediatizar o conjunto do seu trabalho, reduzindo-o a uma relação inanimada de trocas institucionais.

A análise e a deliberação da juíza quanto aos rumos da medida socioeducativa de cada interno, com base, entre outros aspectos, nas Fichas Instrumentais produzidas pelo NE, apontou esse documento como elemento central do processo avaliativo desenvolvido nesse espaço. Essas fichas sobrepõem-se até mesmo às notas/conceitos/menções e ou avanços/aprovações entre os anos escolares, costumeiramente tomados como preocupação maior dos estudantes das escolas da rua $^{4}$. Os julgamentos e as decisões a respeito do rendimento escolar também pareciam importar aos socioeducandos, mas pela possibilidade de constarem na FI, o que os prejudicaria em relação às avaliações judiciais. Declarações de estudantes e professores confirmam tal pressuposto:

\footnotetext{
A avaliação ajuda. Ajuda nós a sair daqui desse lugar. A ganhar nossa liberdade. No relatório ${ }^{5}$ que vai para a juíza, a parte da escola é a melhor, a mais importante 6 . (Estudante)

A avaliação é como se fosse um relatório. Se a avaliação da escola for ruim, o relatório vai subir ruim. $\mathrm{O}$ da escola é o que pesa mais. (Estudante)

A avaliação ajuda, por exemplo... deixa eu pensar... só pra eu ir embora. (Estudante)

Às vezes é um aluno muito difícil. Quando ele solicita o benefício à juíza ele começa a ser maravilhoso. Se não for contemplado ele volta a ser aquele aluno que era antes, irresponsável, desorganizado. (Professora)
}

Mesmo reconhecendo a justeza do anseio por liberdade dos jovens internos e dos esforços por eles movidos nessa direção, o excessivo apelo às Fichas Instrumentais como mecanismo avaliativo capaz de libertá-los fisicamente pode ter contribuído para subtrair do NE a possibilidade 
de favorecer, por meio de um ato educativo desalienante, o alcance da liberdade materializada pelo livre exercício de suas consciências. (FREIRE, 1996).

Centrar nos juízos proferidos a seu respeito na FI, como afirmado pelos estudantes, a justificativa para seus esforços frente ao trabalho escolar, pode conferir artificialidade ao trabalho pedagógico, uma vez que se mostra, assim, voltado a um fim útil cujo alcance não envolve, necessariamente, a conquista de saberes.

Considerando a proeminência da avaliação judicial para os socioeducandos e o fato de que ela se pautava por informações comunicadas a seu respeito, entre outras formas, por meio das Fichas Instrumentais, é possível inferir que a avaliação realizada pelo e no NE registrada nesse instrumento não só influenciava a avaliação da juíza mas era também fortemente influenciada por ela.

Ao serem correlacionadas às análises judiciais as avaliações escolares desenvolvidas no contexto socioeducativo pesquisado assumem um formato diferenciado e ainda mais complexo. Isso potencializa a necessidade de que o desempenho escolar dos socioeducandos seja analisado por todos os profissionais que junto a eles atuam e que envolva todas as informações produzidas a seu respeito. A importância da autoavaliação realizada pelo e no NE se acentua ao permitir, não só o encontro dessas informações para a produção de Fichas Instrumentais coerentes com a realidade, mas também a análise do trabalho pedagógico de modo a organizá-lo e conduzi-lo visando possibilitar a todos, conquistar continuamente novas aprendizagens e promover uma formação voltada mais para a libertação de mentes do que de corpos.

A insatisfação demonstrada pela juíza quanto às informações escolares a ela encaminhadas indicaram haver disfunções que comprometiam o alcance desse propósito. O modo como eram preenchidas as Fichas Instrumentais foi apontado como aspecto indutor de parte delas.

No caso das turmas de Ensino Médio e de Anos Finais do Ensino Fundamental (12 de cada etapa), as Fichas eram preenchidas pelo professor referência de cada uma delas ${ }^{7}$. Esse professor atuava como um representante da turma, respondendo por ela frente às diferentes questões surgidas no $\mathrm{NE}$ ou requeridas por ele, e sua designação era feita no início do ano letivo por meio de sorteio.

Além dos campos que deveriam ser preenchidos pelo professor referência, a FI continha espaços destinados a considerações de outros três professores que eram escolhidos aleatoriamente pelo próprio professor referência. A escolha desses colegas não seguia critérios predefinidos e contava com a disponibilidade de tempo e ou de boa vontade deles para a realização desse trabalho. 
Como nem sempre havia essa solicitude, esses espaços ficavam, por vezes, em branco ou eram preenchidos pelo próprio professor referência.

Mesmo quando complementados com considerações de colegas, os registros das FI configuravam, em sua maioria, impressões individualizadas e pontuais, o que pode constituir impeditivo para que esse instrumento represente, conforme esperado, a visão do NE a respeito do desempenho escolar dos estudantes. Esse modo fragmentado de fazer os registros foi contestado tanto pelas pedagogas das equipes sociopsicopedagógicas quanto pelos próprios professores do NE que apresentaram sugestões de como esse processo deveria acontecer:

Por exemplo, eu acredito que esse relatório ele tinha que ser preenchido pelos professores daquele aluno, todos os envolvidos. A gente tinha que ter uma reunião, um momento só pra preenchimento desses relatórios, que a gente discutisse, que a gente falasse sobre ele... porque há muitas divergências. (Professora)

Eu acho que (a FI) deveria ser preenchida por todos os professores, né, não ter um professor referência pra isso. (Pedagoga da UI)

A individualidade docente que marcou o preenchimento das FI estende-se aos estudantes, isolando-os desse processo, fato por eles aceito com certa naturalidade:

Avaliação é um conceito de todos... um conceito do outro que tá acima sobre nós que tá aqui embaixo. Por quem está acima dentro do estabelecido pela legislação. (Estudante)

Os professor perguntar pra nós? É lenda. Pra mim tanto faz. Tanto faz, tanto fez. Não vai mudar nada. Não muda nada, vai ficar sempre a mesma coisa. Não muda nada. (Estudante)

A superação do antagonismo que, em geral, marca as relações pedagógicas, colocando a avaliação exclusivamente a cargo da autoridade docente, requer o engajamento dos estudantes no processo ensino-aprendizagem, incluindo as práticas avaliativas que o integra. A autoavaliação insere-se nessa perspectiva, uma vez que pode auxiliar o socioeducando a se autoperceber como ser histórico em constante movimento de busca e de descoberta, compreender suas limitações, mas principalmente suas possibilidades, provocando-o à reflexão e à autorregulação.

Isso implica a união entre o ensino dos conteúdos escolares e formação ética, prática e teoria, autoridade e liberdade, ignorância e saber, respeito ao professor e respeito aos estudantes, ensino e aprendizagem (FREIRE, 2015). O exercício da liberdade de se pronunciar a respeito do seu modo de ser e estar no ambiente escolar e sentir suas falas acolhidas para a tomada de decisões 
tende a contribuir para resgatar, ou mesmo construir, nos socioeducandos, o próprio sentido de existência no mundo, algo já bastante deteriorado ou inexistente em grande parte desses jovens.

Embora alvo de críticas, o modo como eram preenchidas as Fichas Instrumentais não foi alvo de reflexões pelo coletivo do NE ou da UI. No entanto, tanto os professores quanto os especialistas da GESPP reconheciam a necessidade de conexão entre os setores da Unidade, especialmente entre eles próprios, para tratar de questões referentes, não somente à FI, mas também ao desenvolvimento dos socioeducandos de uma maneira geral. Foi dito a esse respeito:

Nós precisamos delas (especialistas da GESPP) pra gente estar juntas resolvendo os problemas, mas infelizmente não conseguimos [...]. Pois é, é muito triste, a gente chegar no terceiro bimestre e não ter conseguido. (Coordenadora do NE) Olha, pra mim, quanto mais quiserem vir participar (do trabalho), melhor. (Pedagoga da UI)

A interlocução entre esses setores limitou-se, em grande parte, aos encontros entre o supervisor, os coordenadores do NE e os gestores da UI onde, segundo o supervisor, predominavam assuntos referentes à organização de eventos e ao fluxo da FI. Aconteciam ainda, esporadicamente, visitas dos especialistas ao NE em busca de alguma informação junto ao supervisor ou à coordenadora, ou desses ao setor da Unidade ocupado pela GESPP, pelo mesmo motivo. A participação de pedagogos da equipe sociopsicopedagógica em Conselhos de Classe aconteceu uma única vez ao longo do ano, embora a Coordenadora do Núcleo tenha afirmado que um cronograma com datas e horários era sempre enviado com antecedência à GESPP.

Segundo Villas Boas (2010, p. 42), o conselho de classe é "um órgão colegiado em que atuam os professores das diversas disciplinas, com a equipe pedagógica da escola". No caso do trabalho socioeducativo em que as avaliações escolares se estendem para além do âmbito da escola e podem interferir em decisões definidoras do próprio destino dos socioeducandos, o conselho de classe ganha relevância e sugere a necessidade de ampliação desse espaço. O envolvimento de outros setores da Unidade, em especial da equipe sociopsicopedagógica, indica ser importante, não só para que as análises realizadas no e pelo conselho de classe sejam enriquecidas pelas diferentes visões acerca do desempenho dos socioeducandos, mas também para que o trabalho de ambos os setores se fortaleça visando melhor prover os jovens internos de condições para aprenderem, desenvolverem-se e ganharem de volta a liberdade com condições de usufruir dela com liberdade também de pensamento. O que prevaleceu nesse contexto, no entanto, foi um diálogo entre surdos em que os atores sociais têm suas próprias esferas de ação e não desejam ser incomodados, mas se vigiam mutuamente por meio de suas práticas. (HENRIQUES, 2006). 
Dadas as condições do contexto investigado, prover os estudantes de condições que possibilitem sua participação nas avaliações, seja por meio da FI ou de qualquer outro instrumento/procedimento avaliativo - não como meros espectadores e receptores de informações e decisões, mas como pessoas que compreendem a realidade e que, por isso, têm o que falar e como contribuir para melhorá-la - constitui um desafio que, em nome do compromisso político de promover a autonomia dos socioeducandos em seu processo ressocializador, precisa ser enfrentado sob pena de constituir, para esses jovens, mais uma fonte de desesperança.

Não se pode, no entanto, atribuir à escola a responsabilidade de, sozinha, promover as alterações necessárias ao êxito do trabalho socioeducativo, uma vez que condições extrapedagógicas incidem sobre o processo escolar desenvolvido nesse contexto, inibindo suas possibilidades de sucesso. A fragmentação do trabalho da Unidade e a desarticulação deste com o NE se impôs como mais um obstáculo a ser superado.

\section{Considerações finais}

Ao serem aprisionados, os adolescentes infratores perdem, temporariamente, um dos direitos basilares que cabe aos cidadãos que vivem em nações democráticas, colocando a liberdade em condição de sonho permanentemente alimentado e insistentemente perseguido. Devolver aos adolescentes e jovens internos o pleno exercício de seus direitos é papel social do Estado, e a Socioeducação constitui a atual política pública encarregada desse resgate. Imerso nesse contexto encontra-se o trabalho pedagógico escolar e, mais particularmente, a avaliação desenvolvida junto aos socioeducandos que, pela singular importância que ocupa no processo de ressocialização desses sujeitos, foi tomada como objeto de análise neste artigo.

O justo desejo de liberdade dos jovens presos colocou a avaliação feita pela juíza responsável pelas decisões a respeito do cumprimento da medida socioeducativa no centro do processo avaliativo desenvolvido no e pelo NE. Essa avaliação tornou-se a principal preocupação dos estudantes, contribuindo para distanciar a avaliação praticada naquele contexto de seu propósito maior de promover aprendizagens que auxiliem a reintegração social desses jovens. Notas, aprovações e certificações, que comumente monopolizam as atenções dos estudantes das "escolas da rua", eram também visadas pelos socioeducandos, mas devido à importância desses resultados para sua colocação em libertação pela juíza. A avaliação judicial integra-se, assim, à 
avaliação escolar, revestindo-se do poder necessário para canalizá-la para fins nem sempre associados à construção de aprendizagens, ou seja, para fins distanciados de propósitos formativos.

As influências da avaliação judicial sobre a avaliação realizada no e pelo NE e desta para as análises a respeito do desenvolvimento dos socioeducandos pela juíza reforçam a necessidade de articulação do trabalho desenvolvido entre a escola os demais setores da Unidade de Internação. Como instrumento mediador desse processo, a FI evidenciou relevância em meio à prática avaliativa desenvolvida no e pelo NE, demandando cuidados quanto ao seu uso.

A exposição/apropriação de diferentes informações sobre os estudantes e a respeito do trabalho junto a eles realizado poderia ainda contribuir para que disfunções apontadas pelos interlocutores, ecoassem em forma de reflexões necessárias ao estabelecimento de um pacto em busca de conquistas capazes de superar os diferentes e numerosos entraves interpostos nesse percurso. O ideal neoliberal de alcance do sucesso com base em características e esforços individuais seria, assim, sobreposto por estratégias de união que serviriam à contraposição da subjetividade dominante que condena jovens infratores desconsiderando as condições históricomateriais que configuram suas atuais condições de vida.

Destaca-se que, em contextos de silenciamento, doutrinação e submissão de toda ordem, a necessidade de dar voz aos estudantes se fortalece, sendo a avaliação um processo que pode se constituir em espaço privilegiado de participação. Para isso, é fundamental que jovens privados de liberdade não sejam considerados sujeitos passivos ou passíveis de projetos de terceiros, mas como coarquitetos e principais construtores de projetos educativos transformadores das suas realidades.

\footnotetext{
${ }^{1}$ De acordo com o art. $2^{\circ}$ do Estatuto da Criança e do Adolescente (ECA - Lei no 8.069, de 13 de julho de 1990), é considerada criança toda pessoa até 12 anos incompletos, e adolescente, aquele entre 12 e 18 anos de idade também incompletos. Já o Estatuto da Juventude (Lei no 12.852 de 5 de agosto de 2013) considera jovem pessoas com idade entre 15 e 29 anos de idade. O uso do termo "jovem" em grande parte do texto, para se referir aos estudantes interlocutores do estudo, se justifica, portanto, pelo fato da pesquisa ter sido realizada no interior de uma Unidade de Internação que atende a socioeducandos maiores de 18 anos, uma vez que o período de cumprimento de medidas socioeducativas pode estender-se até os 21 anos de idade (BRASIL, 1990).

${ }^{2}$ Os demais eixos estratégicos são: suporte institucional e pedagógico; diversidade étnico-racial, de gênero e de orientação sexual; cultura, esporte e lazer; saúde; profissionalização/trabalho/previdência; família e comunidade e segurança.

${ }^{3}$ Diretrizes Nacionais para o Atendimento Escolar de Adolescentes e Jovens em Cumprimento de Medidas Socioeducativas $(2015$, p.17).

${ }^{4}$ Expressão utilizada pelos estudantes para referirem-se às escolas que funcionam fora das prisões ou das Unidades de Internação.

${ }^{5}$ Estudantes e professores chamavam de "relatório", tanto a Ficha Instrumental como o Relatório Avaliativo.

${ }^{6}$ As falas dos estudantes foram literalmente transcritas a fim de preservar uma caraterística que se mostrou fortemente distintiva desse segmento, e evidenciar sua não aprendizagem em relação à expressão oral, aspecto que se refletia, quase sempre, na forma escrita.

${ }^{7}$ O Núcleo de Ensino tinha apenas quatro turmas de Anos Iniciais e as Fichas Instrumentais dessas turmas eram preenchidas pelo professor responsável pelo trabalho junto a elas.
} 


\section{Dialogia}

SOARES, Enilvia Rocha Morato; FERNANDES SILVA, Edileuza. Avaliação no contexto socioeducativo: desafios e perspectivas

\section{Referências}

AGUIAR, Wanda Maria Junqueira de. Apreensão dos sentidos: aprimorando a proposta dos núcleos de significação. Revista Brasileira de Estudos Pedagógicos [online], v. 94, n. 236, p. 299-322, 2013. Disponível em: http://www.scielo.br/scielo.php?pid=S2176-

66812013000100015\&script=sci_abstract\&tlng=pt. Acesso em: 15 set. 2016.

AGUIAR, Wanda Maria Junqueira de; OZELLA, Sergio. Núcleos de significação como instrumento para a apreensão da constituição dos sentidos. Psicologia: Ciência e Profissão, Brasília, v. 26, n. 2, p. 222-245, 2006.

AGUIAR, Wanda Maria Junqueira de; SOARES, Júlio Ribeiro; MACHADO, Virgínia Campos. Núcleos de significação: uma proposta histórico-dialética de apreensão das significações. Cadernos de Pesquisa, v. 45, n. 155, p. 56-75, 2015.

BRASIL. Constituição da República Federativa do Brasil. Brasília, DF: Senado Federal, 1988.

BRASIL. Parecer CNE/CEB no 8/2015, aprovado em 7 de outubro de 2015. Diretrizes Nacionais para o Atendimento Escolar de Adolescentes e Jovens em Cumprimento de Medidas Socioeducativas.

BRASIL. Lei no 8.069, de 13 de julho de 1990. Estatuto da Criança e do Adolescente (ECA). Dispõe sobre o Estatuto da Criança e do Adolescente, e dá outras providências. Diário Oficial da União: Seção 1. Brasília, DF, 16 jul. 1990. p. 13563. Disponível em:

http://www.planalto.gov.br/CCIVIL_03/leis/L8069.htm. Acesso em: 17 out. 2014.

BRASIL. Lei no 12.594, de 18 de janeiro de 2012. Institui o Sistema Nacional de Atendimento Socioeducativo (Sinase), regulamenta a execução das medidas socioeducativas destinadas a adolescente que pratique ato infracional. Brasília-DF: Presidência da República, 2012. Diário Oficial da União: Seção 1. Brasília, DF, 19 jan. 2012. p. 3. Disponível em: http://www.planalto.gov.br/ccivil_03/_Ato2011-2014/2012/Lei/L12594.htm. Acesso em: 20 out. 2016.

BRASIL. Câmara dos Deputados. Projeto de Lei n 1.627/07. Dispõe sobre os sistemas de atendimento socioeducativo, regulamenta a execução das medidas destinadas ao adolescente, em razão de ato infracional, altera dispositivos da Lei no 8.069, de 13 de julho de 1990, que dispõe sobre o Estatuto da Criança e do Adolescente, e dá outras providências. Brasília-DF: Câmara dos Deputados, jul. 2007. Disponível em:

https://www.camara.leg.br/proposicoesWeb/fichadetramitacao?idProposicao=360092. Acesso em: 20 out. 2016.

BRASIL. Secretaria Especial dos Direitos Humanos. Sistema Nacional de Atendimento Socioeducativo: SINASE. Brasília, DF: CONANDA, 2006.

CURY, Carlos R. Jamil. Educação e Contradição: Elementos metodológicos para uma Teoria Crítica do Fenômeno Educativo. São Paulo: Cortez: Autores Associados, 1985.

DISTRITO FEDERAL. Secretaria de Estado de Educação do Distrito Federal. Diretrizes Pedagógicas: Escolarização na Socioeducação. Brasília, DF: SEB, 2014. 
FREIRE, Paulo. Educação como Prática da Liberdade. Rio de Janeiro: Paz e Terra, 1996.

FREIRE, Paulo. Pedagogia da Autonomia. Rio de Janeiro: Paz e Terra, 2015.

HADJI, Charles. Avaliação desmistificada. Porto Alegre: Artmed, 2001.

HENRIQUES, Maria Eulália de Faria. Os trabalhos de casa na escola do $1^{\circ}$ ciclo da Luz: Estudo de caso. Interaç̧ões, v. 2, n. 2, p. 220-243, 2006. Disponível em:

https://revistas.rcaap.pt/interaccoes. Acesso em: 19 mar. 2020.

ONOFRE, Elenice Maria Cammarosano. Educação Escolar na Prisão: Controvérsias e Caminhos de Enfrentamento e Superação da Cilada. In: LOURENÇO, Arlindo da Silva; ONOFRE, Elenice Maria Cammarosano (org.). Espaço da Prisão e suas Práticas Educativas. São Carlos: EdUFScar, 2011.

PERRENOUD, Philippe. Avaliação: da excelência à regulação das aprendizagens: entre duas lógicas. Porto Alegre: Artmed, 1999.

SADLER, D. Royce. Formative assessment and the design of instructional systems, Instructional Science, v. 18, p. 119-144, 1989.

SCARFÓ, Francisco José; AUED, Victoria. El derecho a la educación en las cárceles: abordaje situacional. Aportes para la reflexión sobre la educación como derecho humano en contextos de la cárcel. Revista Eletrônica de Educação. São Carlos, SP: UFSCar, v. 7, n. 1, p. 88-98, maio 2013. Disponível em: http://www.reveduc.ufscar.br. Acesso em: 24 jul. 2013.

SCARFÓ, Francisco José; BREGLIA, Florencia; FREJTMAN, Valéria. Sociedade Civil e Educação Pública nos Presídios: Questões para Reflexão. In: LOURENÇO, Arlindo da Silva; ONOFRE, Elenice Maria Cammarosano (org.). Espaço da Prisão e suas Práticas Educativas. São Carlos: EdUFScar, 2011.

SOUZA, Rosimere; BATISTA, Vilnia. Caminhos para a municipalização do atendimento socioeducativo em meio aberto: liberdade assistida e prestação de serviço à comunidade. Rio de Janeiro: IBAM/DES; Brasília: SPDCA/SEDH, 2008. Disponível em: http://www.ibam.org.br/media/arquivos/estudos/atendimento_socioeducativo_1.pdf Acesso em: 07 jun. 2019.

VASCONCELLOS, Celso dos S. Avaliação Classificatória e excludente e a inversão Fetichizada da Função Social da Escola. In: FERNANDES, Claudia de O. (org.). Avaliação das Aprendizagens: sua relação com o papel social da escola. São Paulo: Cortez, 2014.

VILLAS BOAS, Benigna Maria de Freitas. Projeto de Intervenção na Escola: mantendo as aprendizagens em dia. Campinas: Papirus, 2010. 


\section{Dialogia}

SOARES, Enilvia Rocha Morato; FERNANDES SILVA, Edileuza. Avaliação no contexto socioeducativo: desafios e perspectivas

Recebido em: 25 fev. 2020 / Aprovado em: 28 abr. 2020

Cite como (ABNT NBR 6023:2018)

SOARES, Enilvia Rocha Morato; FERNANDES SILVA, Edileuza. Avaliação no contexto socioeducativo: desafios e perspectivas. Dialogia, São Paulo, n. 34, p. 107-121, jan./abr. 2020. Disponível em: https://doi.org/10.5585/Dialogia.N34.16652. 